\title{
57Fe-Mössbauer spectroscopy and electrochemical activities of graphitic layer encapsulated iron electrocatalysts for the oxygen reduction reaction
}

Zhong, Lijie; Frandsen, Cathrine; Mørup, Steen; Hu, Yang; Pan, Chao; Cleemann, Lars Nilausen; Jensen, Jens Oluf; Li, Qingfeng

Published in:

Applied Catalysis B: Environmental

Link to article, DOI:

10.1016/j.apcatb.2017.09.014

Publication date:

2018

Document Version

Peer reviewed version

Link back to DTU Orbit

Citation $(A P A)$ :

Zhong, L., Frandsen, C., Mørup, S., Hu, Y., Pan, C., Cleemann, L. N., Jensen, J. O., \& Li, Q. (2018). ${ }^{57}$ FeMössbauer spectroscopy and electrochemical activities of graphitic layer encapsulated iron electrocatalysts for the oxygen reduction reaction. Applied Catalysis B: Environmental, 221, 406-412.

https://doi.org/10.1016/j.apcatb.2017.09.014

\section{General rights}

Copyright and moral rights for the publications made accessible in the public portal are retained by the authors and/or other copyright owners and it is a condition of accessing publications that users recognise and abide by the legal requirements associated with these rights.

- Users may download and print one copy of any publication from the public portal for the purpose of private study or research.

- You may not further distribute the material or use it for any profit-making activity or commercial gain

- You may freely distribute the URL identifying the publication in the public portal 


\section{${ }^{57}$ Fe-Mössbauer Spectroscopy and Electrochemical Activities of Graphitic Layer} Encapsulated Iron Electrocatalysts for the Oxygen Reduction Reaction

\section{Lijie Zhong1, Cathrine Frandsen ${ }^{2}$, , Steen Mørup², Yang Hu' ${ }^{1}$, Chao Pan¹, Lars Nilausen \\ Cleemann ${ }^{1}$, Jens Oluf Jensen ${ }^{1}$, Qingfeng $\mathrm{Li}^{1, *}$ \\ ${ }^{1}$ Department of Energy Conversion and Storage, Kemitorvet, 207, Technical University of \\ Denmark, DK-2800 Kgs. Lyngby, Denmark. E-mail: qfli@dtu.dk}

${ }^{2}$ Department of Physics, Building 307, Technical University of Denmark, DK-2800 Kgs. Lyngby, Denmark. E-mail: fraca@fysik.dtu.dk

\section{Graphic abstract}
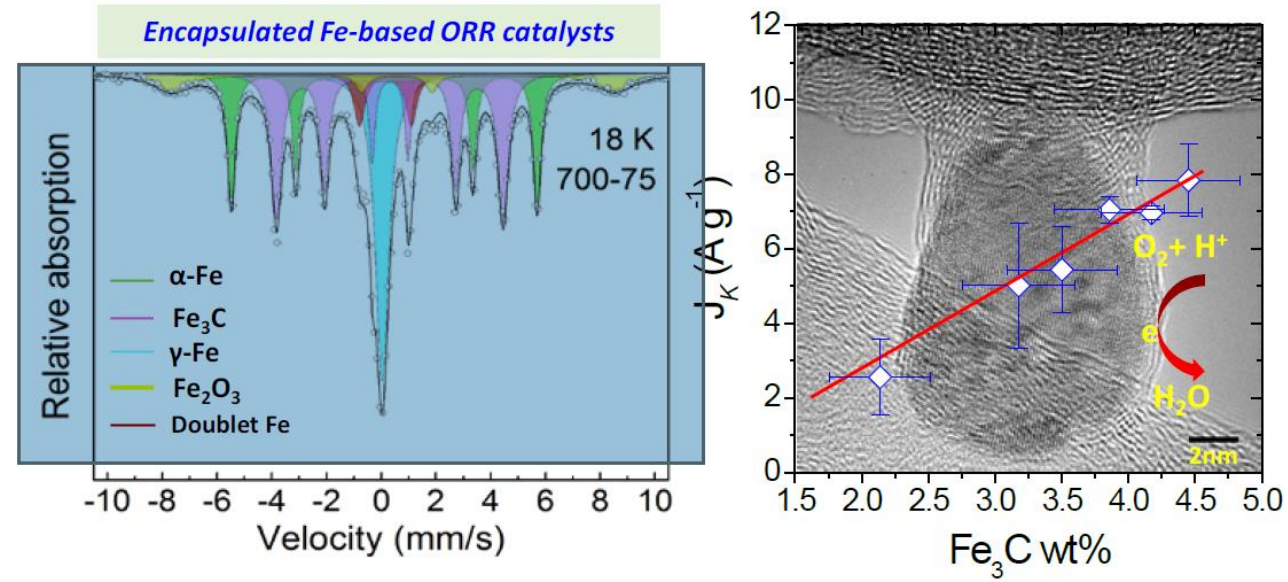

Highlights

- 1. Graphitic layer encapsulated iron based catalysts with varied compositions prepared.

- 2. The components recognized including $\alpha-\mathrm{Fe}, \gamma-\mathrm{Fe}, \gamma-\mathrm{Fe}_{2} \mathrm{O}_{3}, \mathrm{Fe}_{3} \mathrm{C}$ and paramagnetic Fe.

- 3. The catalysts exhibited high ORR activity and stability in acid media.

- 4. Correlations between activity and $\mathrm{Fe}_{3} \mathrm{C}$ content established.

\section{Abstract}


Graphitic layer encapsulated iron based nanoparticles (G@FeNPs) have recently been disclosed as an interesting type of highly active electrocatalysts for the oxygen reduction reaction (ORR). However, the complex composition of the metal-containing components and their contributions in catalysis remain unclear. As a representative catalyst of the unique encapsulated structure, a series of G@FeNPs catalysts were prepared by a high-pressure pyrolytic process with uniform and essentially identical morphologies but varied compositions. The catalysts exhibited a high onset potential of 0.85 $\mathrm{V}$ at $0.1 \mathrm{~mA} \mathrm{~cm}^{-2}$ in acidic media. By ${ }^{57} \mathrm{Fe}$-Mössbauer spectroscopy the iron containing components were identified including $\alpha-\mathrm{Fe}, \gamma-\mathrm{Fe}, \gamma-\mathrm{Fe}_{2} \mathrm{O}_{3}$, and $\mathrm{Fe}_{3} \mathrm{C}$ as well as a minor doublet component due to $\mathrm{Fe}^{3+}$ in high spin and/or $\mathrm{Fe}^{2+}$ in low spin state. The ORR activities are evaluated in terms of the mass specific kinetic current density found to be positively correlated with the $\mathrm{Fe}_{3} \mathrm{C}$ content in the range of study, indicating involvement of the encapsulated nanoparticles in the ORR catalysis. The recognition of the Fe compositions and active sites provides new insights to the confined Fe-based ORR electrocatalysts and therefore options for further development of non-precious metal materials.

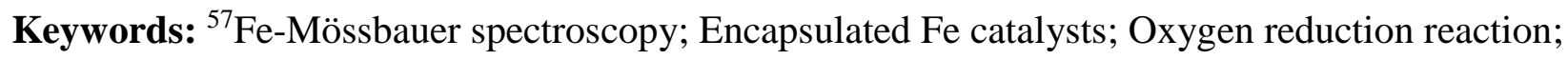
Fuel cells

\section{Introduction}

A core subject of the proton exchange membrane fuel cell (PEMFC) has been the development of alternative cathodic electrocatalysts for the oxygen reduction reaction (ORR) to replace the currently used platinum-based catalysts. The past decades have witnessed the remarkable progress on non-precious metal catalysts (NPMCs), since the pioneering work of Co phthalocyanine was introduced by Jasinski [1]. An interesting type of materials is transition metal-based NPMCs in the form of metal-nitrogen-carbon composites (M-N-C) typically synthesized by pyrolysis [2-9]. The precursors have largely been expanded from the early macrocycle molecules such as phthalocyanines and porphyrins to a wide variety of small molecules containing nitrogen, carbon and transition metals. Breakthroughs have been achieved, for example, by the polyaniline-derived Fe-N-C with improved durability due to the low $\mathrm{H}_{2} \mathrm{O}_{2}$ yield [4], and microporous carbon supported $\mathrm{Fe}-\mathrm{N}-\mathrm{C}$ resulting from an optimized two-step pyrolysis process with high catalytic activity [2]. Exploration of active sites has suggested that the key active motifs are the $\mathrm{Fe}^{2+}$ atoms coordinated with four nitrogen atoms embedded in the in-plane carbon $\left(\mathrm{Fe}^{2+} \mathrm{N}_{4} / \mathrm{C}\right)$ [10-11]. This type of NPMCs exhibits high ORR activity while the stability remains the currently focused issue. 
High temperature pyrolysis of iron containing precursors, in fact, involves formation of carbon around iron nanoparticles, since the amorphous carbon dissolves in the iron phase and then assembles into graphitic carbon by atomic diffusion to the surface [12]. It is therefore natural that the pyrolytic catalysts often contain some encapsulated metallic nanoparticles [13]. Several research groups have attempted to synthesize NPMCs of the encapsulated structures. Deng et al. first demonstrated that pod-like iron nanoparticles confined in carbon nanotubes (CNTs) exhibited significant ORR activity and particularly for the stability [14]. Other metal containing components such as inorganic $\mathrm{Fe}_{3} \mathrm{O}_{4}[15], \mathrm{Fe}_{3} \mathrm{C}[16,17]$ and $\mathrm{Fe} / \mathrm{Fe}_{3} \mathrm{C}$ [18] have also been reported in the carbon-encapsulated structures. Recently, a novel approach of high-pressure pyrolysis by $\mathrm{Hu}$ et al. allowed for preparation of a typical catalyst of ironcontaining nanoparticles in the graphitic layer encapsulated structure [19]. Characteristics of the materials include uniform iron containing nanoparticles, in a mass content range of over $10 \%$, encapsulated in CNTs [20] or/and graphene layers [21]. The encapsulating carbon layers are likely due to the high pyrolytic pressure, curved into hollow microspheres.

For the encapsulated NPMCs, the catalytic contribution of those encapsulated metal containing phases is currently still much debated. On one hand, the interaction of the $\mathrm{FeN}_{\mathrm{x}} / \mathrm{C}$ sites with encapsulated metal containing particles was emphasized [22], which is believed to boost the ORR activity. On the other hand, removal of the inorganic metal species from the Fe-N-C catalyst was found to enhance the ORR activity [23]. Very recently, a novel approach by $\mathrm{Cl}_{2}$ etching and $\mathrm{H}_{2}$ restoring provides encouraging results for understanding the active site [24]. The authors prepared encapsulated $\mathrm{Fe}$-based catalysts that contain $\mathrm{FeN}_{\mathrm{x}} / \mathrm{C}$ and confined $\mathrm{Fe}$ species. $\mathrm{By}$ using $\mathrm{Cl}_{2}$ etching, both $\mathrm{FeN}_{\mathrm{x}} / \mathrm{C}$ and confined $\mathrm{Fe}$ species were converted into $\mathrm{FeCl}_{3}$ and the ORR activity was lost. Further, this treated sample underwent $\mathrm{H}_{2}$ reduction. Due to $\mathrm{N}$-containing species removed in $\mathrm{Cl}_{2}$ etching, the $\mathrm{FeCl}_{3}$ can only be converted into Fe species, which excludes the existence of $\mathrm{FeN}_{\mathrm{x}} / \mathrm{C}$. The recovery of ORR activity after $\mathrm{H}_{2}$ reduction demonstrates the active sites of encapsulated Fe species. This encouraging result indicates the active contribution of the inner Fe phases. Further identification of the Fe phases and correlations of the iron components with the electrochemical activity should be very informative.

In our previous work, a series of graphitic layer encapsulated iron nanoparticles (G@FeNPs) catalysts were, by varying temperature and duration of the high-pressure pyrolysis, prepared with essentially identical morphologies but different compositions [25]. The present paper is devoted to a ${ }^{57} \mathrm{Fe}-$ Mössbauer spectroscopy study on various $\mathrm{Fe}$ 
components of the wrapped metal-containing phases. The identified metal components include $\alpha-\mathrm{Fe}, \gamma-\mathrm{Fe}, \gamma-\mathrm{Fe}_{2} \mathrm{O}_{3}, \mathrm{Fe}_{3} \mathrm{C}$ as well as a minor component due to (super)paramagnetic $\mathrm{Fe}^{3+}$ (high spin) and/or paramagnetic $\mathrm{Fe}^{2+}$ (low spin). In terms of the kinetic current density, the ORR activity of the materials was evaluated. The variation of the ORR activity was found to positively correlate with the content of $\mathrm{Fe}_{3} \mathrm{C}$. This experimental evidence relating to encapsulated $\mathrm{Fe}_{3} \mathrm{C}$ to the ORR activity brings new insights to the current understanding of the active sites and opens avenues to further development of high performance non-precious metal catalysts.

\section{Experimental Section}

G@FeNPs preparation. The G@FeNPs catalysts were synthesized by a high-pressure pyrolysis approach. The autoclave reactor was made of modified stainless steel Swagelok® valve parts with a quartz cup $(3.3 \mathrm{ml})$. A mixture of cyanamide and ferrocene in a mass ratio of 9:1 was first well mixed and transferred to the quartz cup in the autoclave in an oxygen-free glove box. The autoclave was then tightly closed and placed into the furnace, which was pre-heated to the desired temperature and held for a certain period. The pressure inside the reactor was estimated to be around 500-600 bars by assuming formation of small gaseous molecules of the precursors during the pyrolysis, which was approximately agreement with estimation by the water vapour test [25].

Two series of catalysts were synthesized with varied pyrolytic temperatures and durations. The first series of catalysts were pyrolyzed at temperatures of 600,700 and $800{ }^{\circ} \mathrm{C}$ for 35 minutes and the second were prepared at a fixed temperature of $700{ }^{\circ} \mathrm{C}$ for varied durations from 15 to 240 minutes. The samples are named after the pyrolytic temperature (in ${ }^{\circ} \mathrm{C}$ ) and duration (in min), for example, sample $700-75$ was pyrolyzed at $700^{\circ} \mathrm{C}$ for $75 \mathrm{~min}$.

Transmission electron microscopy (TEM) was performed on Tecnai-T20-G2 at 200KV. XRay diffraction was performed on a Philips PW1700 diffract-meter using a $\mathrm{Cu} K \alpha(\lambda=1.5405$ Ả) radiation source.

${ }^{57}$ Fe Mössbauer spectra were measured at both room temperature (295 K) and low temperature (18 $\mathrm{K})$ using a ${ }^{57} \mathrm{Co}$ source embedded in a rhodium matrix and a constant accelerator spectrometer. The isomer shifts were given relative to that of $\alpha$-Fe at room temperature. The samples for Mössbauer spectroscopy were prepared by pressing ca. $100 \mathrm{mg}$ of the sample powder in to pill-shapes $15 \mathrm{~mm}$ in diameter and $2 \mathrm{~mm}$ thick. 
Electrochemical measurements. Electrochemical tests were carried out in a standard threeelectrode cell, a $5.0 \mathrm{~mm}$ glassy carbon disk and a carbon rod were used as the working electrode and counter electrode, respectively. The reference electrode was a saturated calomel electrode (SCE). The potential was converted into a reversible hydrogen electrode (RHE) afterwards. All the electrochemical experiments were performed on a Versa STAT3 (Princeton Applied Research) and 760C Bipotentiostat (CH Instruments) in $\mathrm{N}_{2}$ or $\mathrm{O}_{2}$-saturated $\mathrm{HClO}_{4}$ solution. The commercial Johnson Matthey $20 \% \mathrm{Pt} / \mathrm{C}$ was chosen as the reference catalyst. A catalyst ink was prepared by dispersing $10 \mathrm{mg}$ of catalyst into a mixed solution of $514 \mu \mathrm{L}$ ethanol and $80 \mu \mathrm{L}$ of $5 \%$ Nafion. The ink was applied on the glassy carbon rotating disk electrode (RDE) or rotating ring-disk electrode (RRDE) followed by drying in air. The catalyst loading of the Pt/C catalysts for both RDE and RRDE was $0.25 \mathrm{mg} \mathrm{cm}^{-2}$ while that of the G@FeNP catalysts was $0.65 \mathrm{mg} \mathrm{cm}^{-2}$. The kinetic current density $\left(j_{\mathrm{K}}, \mathrm{mAcm}^{-2}\right)$ was derived from the RDE measurements using the Koutecky-Levich equation:

$$
\frac{1}{j}=\frac{1}{j_{K}}+\frac{1}{j_{L}}
$$

where $j$ and $j_{\mathrm{L}}$ are the measured current and diffusion limiting current density, respectively. The mass kinetic current density is further normalized to the total catalyst mass $\left(J_{\mathrm{K}}, \mathrm{A} \mathrm{g}^{-1}\right)$, which is the same $\left(0.65 \mathrm{mg} \mathrm{cm}^{-2}\right)$ for all samples. For the RRDE measurements, the disk electrode was scanned at a rate of $10 \mathrm{mV} \mathrm{s}^{-1}$, and the ring potential was held constant at $1.2 \mathrm{~V}$ vs. RHE. The $\mathrm{H}_{2} \mathrm{O}_{2} \%$ and transferred electron number per oxygen molecule $(n)$ were calculated by the followed equations:

$$
\begin{aligned}
\mathrm{H}_{2} \mathrm{O}_{2} \%=200 \frac{I_{r} / N}{I_{d}+I_{r} / N} \\
n=4 \frac{I_{d}}{I_{d}+I_{r} / N}
\end{aligned}
$$

where $I_{\mathrm{d}}$ is the disk current and $I_{\mathrm{r}}$ the ring current, and $N$ is the current collection efficiency of the Pt ring, which was determined to be 0.37 .

\section{Results}

\subsection{Encapsulated structure}

General characterization of the two series of G@FeNPs catalysts with varied pyrolysis temperature and duration was reported previously [25]. A brief highlight is given here, which provides a basis for 
the present study focusing on the encapsulated iron components and active sites by ${ }^{57} \mathrm{Fe}$-Mössbauer spectroscopy.

TEM characterization reveals that pyrolysis of ferrocene and cyanamide at $600{ }^{\circ} \mathrm{C}$ involves polymerization of the cyanamide, leading to formation of melamine-rich microspheres with ferrocene dispersed evenly in the spheres (Figure 1). The pyrolytic temperature has a significant impact on the morphology of the catalysts. At $600{ }^{\circ} \mathrm{C}$, microspheres around 500-700 nm in diameters were formed (Figure 1a). At $700{ }^{\circ} \mathrm{C}$, the microspheres maintain their morphologies but become porous as the precursors start to gradually decompose. Metal or metal carbide from decomposition of ferrocene catalyze the carbon deposition, leading to formation of uniformly distributed iron-containing nanoparticles encapsulated by the carbon layers (Figure 1c). When the temperature was further increased to $800{ }^{\circ} \mathrm{C}$, the microspheres were found to be less regular in shape (Figure 1h). When the temperature is fixed at $700{ }^{\circ} \mathrm{C}$, a pyrolytic duration of 15-35 minutes does not seem to be sufficient to achieve complete decomposition of the precursors. After pyrolysis for longer than 35 minutes, the microspheric morphology of the catalysts exhibits little change though the size of the porous spheres becomes small (Figure 1c-g). The high-resolution TEM demonstrates a well-defined encapsulated structure by a few graphitic layers (ca. $2 \mathrm{~nm}$ ) (Figure 1i).

Overall, using volatile small molecules of ferrocene and cyanamide as precursors, the pyrolysis temperature of $700{ }^{\circ} \mathrm{C}$ and duration of $35 \mathrm{mins}$ are the cutting-off conditions for forming G@FeNPs. The high-pressure pyrolysis leads to formation of hollow micro-spheres in the size of 300-400 nm. The spheres are constituted of uniform Fe-containing nanoparticles of typically $10-20 \mathrm{~nm}$, encapsulated in graphitic layers. The encapsulation structure is essential for stabilizing the nanoparticles from the chemical dissolution in acidic solutions during the acid leaching as well as the electrochemical evaluation. As to be discussed below, significant changes in compositions of these iron-containing components are in fact observed and quantified by ${ }^{57} \mathrm{Fe}-\mathrm{Mössbauer}$ spectroscopy.

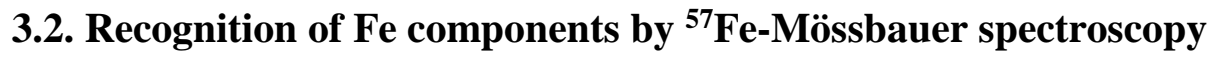

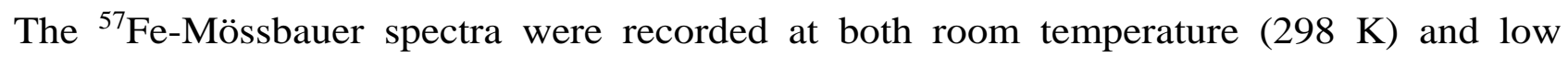
temperature (18 K). Mössbauer spectra for typical samples (700-35, 700-75 and 700-240) are shown in Figure 2. Spectra of additional samples and ferrocene precursor material are shown in Supplemental Material (Figure S1). The spectra were fitted with three sextets, one doublet and one singlet. The parameters, estimated at $18 \mathrm{~K}$ and $295 \mathrm{~K}$ from the spectra of 700-35, 700- 
75, 700-115, 700-180, 700-240 and 800-35, are given in Table 1. Because of the strong overlap of the lines, it was necessary to make some constraints of the parameters. For the sextet fit, the line widths and the line intensities were constrained to be pairwise identical and the relative areas were constrained to be $3: 2: 1: 1: 2: 3$. In the fits of the doublets, the widths and intensities of the two lines were constrained to be identical.

The parameters of sextet 1 (green) are in accordance with those of $\alpha-\mathrm{Fe}[26,27]$ and the parameters of sextet 2 (magenta) are in accordance with those of $\mathrm{Fe}_{3} \mathrm{C}[10,26]$. The isomer shift and the magnetic hyperfine field of sextet 3 (yellow, only seen in the spectra obtained at $18 \mathrm{~K}$ ) suggest that this component can be assigned to $\mathrm{Fe}^{3+}$ in the form of nanoscale $\gamma-\mathrm{Fe}_{2} \mathrm{O}_{3}$, which is likely originated from the atmospheric oxidation of the samples after pyrolysis, as iron nanoparticles are well known to form a passivation layer of maghemite or magnetite when exposed to air [28,29]. At $295 \mathrm{~K}$, this sextet has disappeared, presumably because it has transformed to a quadrupole doublet (part of the red doublet) because of fast superparamagnetic relaxation. The singlet component (turquoise) is due to $\gamma$-Fe [26], which is paramagnetic at room temperature but antiferromagnetic with a very small magnetic hyperfine field at low temperature. This small hyperfine field explains the increased line width at $18 \mathrm{~K}$.

The doublet component (red) has a relatively small intensity at $18 \mathrm{~K}$ for pyrolytic duration longer than $35 \mathrm{~min}$ (e.g. 700-75 and 700-240) and the lines have overlap with the sextet lines (Figures 2c-f). Because of the low intensity and the overlap with other components, the uncertainty of the parameters for this doublet is high. The isomer shift and quadrupole splitting indicate that the doublet is due to $\mathrm{Fe}^{3+}$ in the high spin (HS) state [26,30] and/or $\mathrm{Fe}^{2+}$ in the low spin (LS) state $[10,27,31,32]$. The relative area of the doublet at $295 \mathrm{~K}$ is larger than at $18 \mathrm{~K}$, because it has a contribution from superparamagnetic maghemite. It is likely that this doublet contains contributions from different phases. It is also noted that, for samples prepared at very low temperature (600-35) or for short pyrolysis times (15-35 min) at $700{ }^{\circ} \mathrm{C}$, this doublet is most abundant and has a quadrupole splitting of about $1.3 \mathrm{~mm} \mathrm{~s}^{-1}$ (Figures $\mathbf{2 a} \boldsymbol{\&} \mathbf{b}$ as well as S1, and Table 2). For samples prepared at $700{ }^{\circ} \mathrm{C}$ with longer duration ( $\geq 75 \mathrm{~min}$ ) the doublet becomes less abundant and the quadrupole splitting is around $0.9-1.0 \mathrm{~mm} \mathrm{~s}^{-1}$ (Figures 2c-f). The possibility of an $\mathrm{Fe}^{2+}$ low spin component was included in the fits, which was normally recognized as $\mathrm{Fe}^{2+} \mathrm{N}_{4} / \mathrm{C}(\mathrm{LS})$ in literature $[10,27,31,32]$, but it turned out that the relative area was too small to obtain an unambiguous conclusion. It is apparent that this 
component may represent a mixture of phases containing either remaining precursors or initially formed intermediates in addition to any $\mathrm{FeN}_{x} / \mathrm{C}$ coordination sites. In the present work, no attempt was made to assign this doublet component to any specific compound(s) but we refer it to as the doublet Fe component in the following discussion.

\subsection{Quantitative analysis of iron components}

The relative amounts of iron in different phases were calculated from Mössbauer spectra obtained at $18 \mathrm{~K}$ with assumption of identical Lamb-Mossbauer factors. In parallel, the total iron content was determined by inductively coupled plasma mass spectrometry (ICP-MS) [25] based on which the amount of each phase was estimated from the Mössbauer analysis, as shown in Figure 3. It is seen that the content of the reduced Fe form ( $\alpha$-Fe and $\gamma$-Fe) is steadily increasing with the pyrolytic time (at $700{ }^{\circ} \mathrm{C}$ ) as well as pyrolytic temperature (the solid squares at $800{ }^{\circ} \mathrm{C}$ ). The content of the doublet $\mathrm{Fe}$, as obtained from the low temperature spectra, quickly decreases as the pyrolytic time increases from 35 to $75 \mathrm{~min}$. This indicates that a major component of the mixture phase is probably associated with the remaining precursors or the initially formed intermediates and therefore disappears when approaching the complete decomposition of the $\mathrm{N}$-containing cyanamide With a pyrolysis time of $75 \mathrm{~min}$, the overall $\mathrm{N}$ content was about 4.1 mass $\%$ of the catalysts, and further decreased down to 2.3 mass \% at $240 \mathrm{~min}$. At higher pyrolytic temperature of $800{ }^{\circ} \mathrm{C}$ as low as 1.9 mass\% $\mathrm{N}$ was detected [25]. It is of special interest that the $\mathrm{Fe}_{3} \mathrm{C}$ content was found to peak at the pyrolytic time of $75 \mathrm{~min}$ with fast increase before and slow decrease after this point.

\subsection{ORR electrochemical evaluation}

The ORR polarization curves obtained on the rotating disk electrode for G@FeNPs in acid media are shown in Figure 4a. The samples pyrolyzed at below $700{ }^{\circ} \mathrm{C}$ with little formation of metallic sites showed no ORR activities while a prominent enhancement was observed for sample 700-15. For sample 700-35, the ORR activity was remarkably enhanced. The halfwave potential $\left(\mathrm{E}_{1 / 2}\right)$ increased with the pyrolytic time from 15 to $35 \mathrm{~min}$, peaked for sample 700-75 and then followed the order of 700-115> 800-35> 700-180>700-240. The 700-75 sample exhibited also the highest onset potential of $0.85 \mathrm{~V}$ (at $0.1 \mathrm{~mA} \mathrm{~cm}^{-2}$ ) (Figure 4a), which was further increased to $0.87 \mathrm{~V}$ at higher catalyst loadings $\left(1.03 \mathrm{mg} \mathrm{cm}^{-2}\right.$, Figure $\left.4 \mathbf{b}\right)$.

The rotating-ring-disk-electrode (RRDE) measurement showed a very low $\mathrm{H}_{2} \mathrm{O}_{2}$ yield (ca. $3.5 \%$ ) and an electron transfer number (ET No.) of 3.9 for the 700-75 sample (Figure 4c). In 
addition, the stability of the catalysts was found to have a small degradation by a $25 \mathrm{mV}$ shift of the $E_{1 / 2}$ after 10,000 cycles from the potential between 0.6-1.0 V (vs RHE) [25].

Compared with recent literatures of similar encapsulated structures [14-16,18,33], the present catalysts show relatively high activity and excellent stability in acid media. Table 2 summarizes the results for all samples discussed above. The mass kinetic current density $\left(J_{\mathrm{K}}\right)$, obtained within the kinetically dominated potential region of around $0.7 \mathrm{~V}$, is normalized to the total catalyst mass of $0.65 \mathrm{mg} \mathrm{cm}^{-2}$ and plotted in Figure 4d, where a peak value is observed for sample 700-75. This kinetic current density will be used for the following examination of ORR active correlations.

\subsection{Identification of $O R R$ active sites}

Figure 5. Identification of ORR active sites. (a) Mass specific kinetic current density $J_{\mathrm{k}}$ at $0.70 \mathrm{~V}$ vs. RHE and the $\mathrm{Fe}_{3} \mathrm{C}$ content for samples prepared by pyrolysis at $700^{\circ} \mathrm{C}$ for varied durations and $800^{\circ} \mathrm{C}$ for 35 minutes. (b-f) mass specific kinetic current density $J_{\mathrm{k}}$ at $0.70 \mathrm{~V}$ vs. RHE as a function of the content of various identified $\mathrm{Fe}$ components including $\alpha-\mathrm{Fe}, \mathrm{Fe}_{3} \mathrm{C}, \gamma-\mathrm{Fe}$, the doublet mixture phase and $\mathrm{Fe}_{2} \mathrm{O}_{3}$. Error bars were obtained from standard deviation of 3-5 independent RDE measurements for each catalyst.

Plots similar to Figure $\mathbf{5 b}$ are presented for other iron containing components in Figures $\mathbf{5 c - f}$. It should be remarked that the Fe content is the total amount of the specific iron component in the catalyst samples, expressed as mass \% of the total catalyst, as obtained from the Mössbauer and ICPMS analysis [25].

For the doublet Fe component, a positive trend was also observed except for 700-35 (Figure 5e), though the content is not far beyond the uncertainty range of the Mössbauer analysis. It should be remarked that samples 600-35, 700-15 and 700-35 showed high doublet Fe contents but no or very poor ORR activity. It is assumed that these samples, as prepared from low temperatures and short pyrolytic times, contained an initially formed intermediate phase, which was then converted to the active $\mathrm{FeN}_{\mathrm{x}} / \mathrm{C}$ coordination sites during the prolonged pyrolysis. Overall, an important finding is the positive correlation of the doublet phase and $\mathrm{Fe}_{3} \mathrm{C}$ contents with the ORR activity, suggesting that the two metal containing components are involved in the active sites. Considering the very low content and small change of the doublet Fe phase, the notable variation of the ORR activities of these samples is assumed to be primarily correlated with the $\mathrm{Fe}_{3} \mathrm{C}$ content. No ORR activity contribution from the other inorganic Fe-phases like $\alpha-\mathrm{Fe}, \gamma$-Fe and $\gamma-\mathrm{Fe}_{2} \mathrm{O}_{3}$ can be concluded. 
Because of its poor chemical stability especially in acidic electrolytes, the confined Fe species can only exist in the subsurface to the carbon layers. Previous experimental and theoretical results indicated the encapsulated Fe species exhibited activity via synergies with those surface functionalities [34]. The density function theory calculations revealed that the interaction between Fe and carbon in the CNT walls significantly enhances the activity towards the ORR [14]. Recently reported formation of $\mathrm{Fe} / \mathrm{Fe}_{3} \mathrm{C}$ nanoparticles in the neighbourhood of the Fe-N coordination sites was found to promote the catalytic activity [22]. In addition, the $\mathrm{Cl}_{2}$-etching and $\mathrm{H}_{2}$-restoring approach strongly indicates the function of encapsulated iron species [24]. However, it remains unknown that which type of encapsulated $\mathrm{Fe}$ is the real active component. The present results indicate that the $\mathrm{Fe}_{3} \mathrm{C}$ among those complex Fe-containing components is the one responsible for the possible synergies through the surface carbon layer.

It is worth mentioning that the attempted pyrolysis of $\mathrm{N}$-free precursors (ferrocene and durene) [25] gave poorly defined morphologies and reduced Fe components with some but limited ORR activity. Post treatment of the $\mathrm{N}$-free materials under an $\mathrm{NH}_{3}$ atmosphere improved the ORR activity but remained lower than that of the present catalysts.

\section{Conclusions}

By varying temperature and duration of the high-pressure pyrolysis a series of catalysts were prepared with uniform spherical morphologies of graphitic layer encapsulated iron based nanoparticles (G@FeNPs) but varied contents of metal containing components. The catalysts exhibited excellent catalytic activities towards ORR in acidic media. By means of ${ }^{57} \mathrm{Fe}-$ Mössbauer spectroscopy the iron containing components were identified including $\alpha-\mathrm{Fe}, \gamma$-Fe, $\gamma-\mathrm{Fe}_{2} \mathrm{O}_{3}, \mathrm{Fe}_{3} \mathrm{C}$ as well as a paramagnetic Fe mixture phase, the content of which were estimated. Establishment of correlation of the ORR activities, in terms of the mass specific kinetic current density, with the content of various metal containing components was attempted. $\mathrm{The}^{\mathrm{Fe}}{ }_{3} \mathrm{C}$ content, within the entire studied composition range, showed a strong correlation with the ORR catalytic activity, indicating possible involvement of the nanoparticles in the ORR catalysis. Little correlation of the activity was found with other iron components present in the catalysts.

\section{Acknowledgements}


This work has received financial support from Innovation Fond Denmark (4M Centre 0603 00527B and Non-Precious 4106-00012B) and ForskEL program (UPCAT 2015-1-12315).

\section{References}

[1] R. Jasinski, Nature, 201 (1964), 1212-1213.

[2] M. Lefevre, E. Proietti, F. Jaouen and J.-P. Dodelet, Science, 324 (2009), 71-74.

[3] Z. Chen, D. Higgins, A. Yu, L. Zhang and J. Zhang, Energy Environ. Sci., 4 (2011), $3167-$ 3192.

[4] G. Wu, K. L. More, C. M. Johnston and P. Zelenay, Science, 332 (2011), 443-447.

[5] G. Wu and P. Zelenay, Acc. Chem. Res., 46 (2013), 1878-1889.

[6] W. Xia, A. Mahmood, Z. Liang, R. Zou and S. Guo, Angew. Chem., Int. Ed., 55 (2015), 26502676.

[7] W. Gu, L. Hu, J. Li and E. Wang, J. Mater. Chem. A, 4 (2016), 14364-14370.

[8] J. Li, S. Ghoshal, W. Liang, M. T. Sougrati, F. Jaouen, B. Halevi, S. McKinney, G. McCool, C. Ma and X. Yuan, Energy Environ. Sci., 9(2016), 2418-2432.

[9] C. R. Raj, A. Samanta, S. H. Noh, S. Mondal, T. Okajima and T. Ohsaka, J. Mater. Chem. A, 4 (2016), 11156-11178.

[10] U. I. Kramm, M. Lefevre, N. Larouche, D. Schmeisser and J.-P. Dodelet, J. Am. Chem. Soc., 136 (2014), 978-985.

[11] A. Zitolo, V. Goellner, V. Armel, M.-T. Sougrati, T. Mineva, L. Stievano, E. Fonda and F. Jaouen, Nat. Mater., 14 (2015), 937-942.

[12] J. Wang, H. Wu, D. Gao, S. Miao, G. Wang and X. Bao, Nano Energy, 13 (2015), 387-396.

[13] H. T. Chung, J. H. Won and P. Zelenay, Nat. Commun., 4 (2013), 1922.

[14] D. Deng, L. Yu, X. Chen, G. Wang, L. Jin, X. Pan, J. Deng, G. Sun and X. Bao, Angew. Chem., Int. Ed., 52 (2013), 371-375.

[15] J. Liang, R. F. Zhou, X. M. Chen, Y. H. Tang and S. Z. Qiao, Adv. Mater., 26 (2014), 60746079 .

[16] W. Yang, X. Liu, X. Yue, J. Jia and S. Guo, J. Am. Chem. Soc., 137 (2015), 1436-1439.

[17] B. Y. Guan, L. Yu and X. W. Lou, Energy Environ. Sci., 9 (2016), 3092-3096.

[18] J. Wang, G. Wang, S. Miao, X. Jiang, J. Li and X. Bao, Carbon, 75 (2014), 381-389.

[19] Y. Hu, J. O. Jensen, W. Zhang, L. N. Cleemann, W. Xing, N. J. Bjerrum and Q. Li, Angew. Chem., Int. Ed., 53 (2014), 3675-3679. 
[20] Y. Hu, J. O. Jensen, W. Zhang, S. Martin, R. Chenitz, C. Pan, W. Xing, N. J. Bjerrum and Q. Li, J. Mater. Chem. A, 3 (2015), 1752-1760.

[21] Y. Hu, J. O. Jensen, W. Zhang, Y. Huang, L. N. Cleemann, W. Xing, N. J. Bjerrum and Q. Li, ChemSusChem, 7 (2014), 2099-2103.

[22] W.-J. Jiang, L. Gu, L. Li, Y. Zhang, X. Zhang, L.-J. Zhang, J.-Q. Wang, J.-S. Hu, Z. Wei and L.-J. Wan, J. Am. Chem. Soc., 138 (2016), 3570-3578.

[23] U. I. Kramm, I. Herrmann-Geppert, J. Behrends, K. Lips, S. Fiechter and P. Bogdanoff, J. Am. Chem. Soc., 138 (2016), 635-640.

[24] J.A. Varnell, C. Edmund, C.E. Schulz, T.T. Fister, R.T. Haasch, J. Timoshenko, A.I. Frenkel, A.A. Gewirth, Nat. Commun., 7 (2016), 12582.

[25] L. Zhong, Y. Hu, J. Sværke, C. Pan, L. N. Cleemann, J. O. Jensen, Q. Li, Int. J. Hydrogen Energy (2017), http://dx.doi.org/10.1016/j.ijhydene.2017.07.093

[26] B. David, N. Pizurova, O. Schneeweiss, V. Kudrle, O. Jasek and P. Synek, Jpn. J. Appl. Phys., 50 (2011), 08JF11.

[27] U. I. Kramm, I. Abs-Wurmbach, I. Herrmann-Geppert, J. Radnik, S. Fiechter and P. Bogdanoff, J. Electrochem. Soc., 158 (2011), B69-B78.

[28] L. T. Kuhn, A. Bojesen, L. Timmermann, M. M. Nielsen and S. Mørup, J. Phys.: Condens. Matter, 14 (2002), 13551-13567.

[29] A. Scrimshire, A. L. Lobera, R. Kultyshev, P. Ellis, S. D. Forder and P. A. Bingham, Croat. Chem. Acta, 88 (2015), 531.

[30] P. Gütlich, E. Bill and A. X. Trautwein, Mössbauer Spectroscopy and Transition Metal Chemistry, Springer, Heidelberg, 2011.

[31] U. I. Kramm, J. Herranz, N. Larouche, T. M. Arruda, M. Lefevre, F. Jaouen, P. Bogdanoff, S. Fiechter, I. Abs-Wurmbach, S. Mukerjee and J.-P. Dodelet, Phys. Chem. Chem. Phys., 14 (2012), 11673-11688.

[32] U. I. Kramm, M. Lefevre, P. Bogdanoff, D. Schmeisser and J. P. Dodelet, J. Phys. Chem. Lett., 5 (2014), 3750-3756.

[33] Y. Zhu, B. Zhang, X. Liu, D.-W. Wang and D. S. Su, Angew. Chem., Int. Ed., 53 (2014), 10673-10677.

[34] G. Y. Zhong, H. J. Wang, H. Yu and F. Peng, J. Power Sources, 286 (2015), 495-503. 


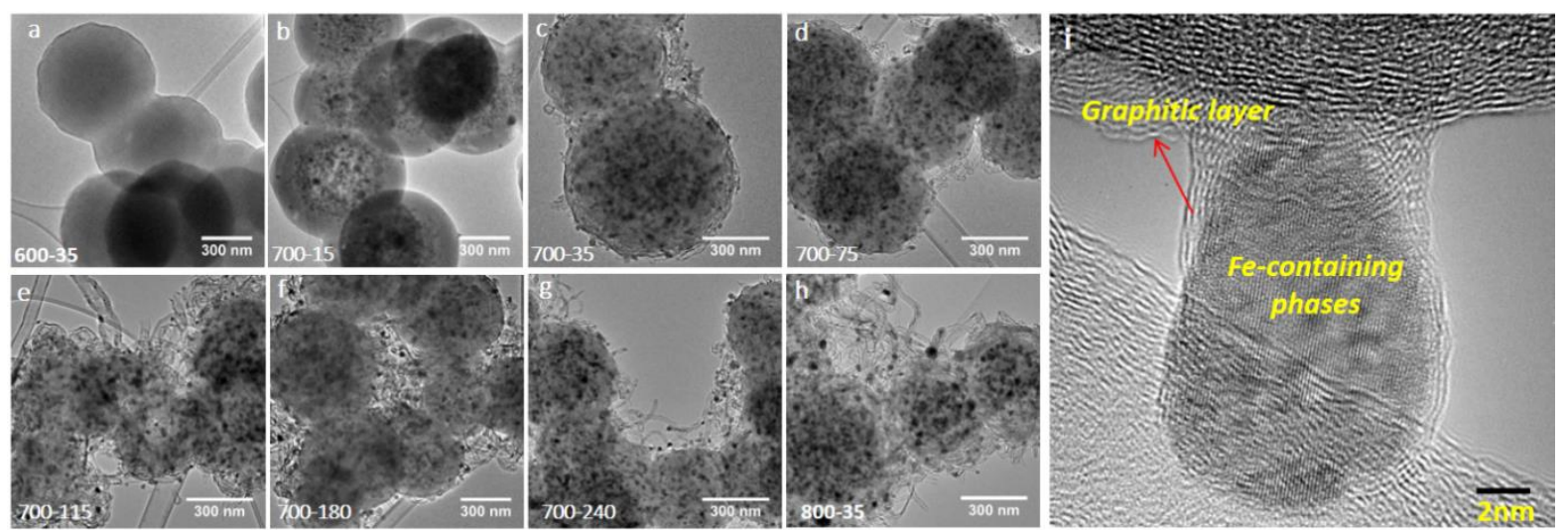

Figure 1. (a-h) TEM images for the G@FeNPs prepared at different pyrolysis temperatures and varied durations as indicated in the figure. (i) A representative HRTEM image for G@FeNPs (700-75).
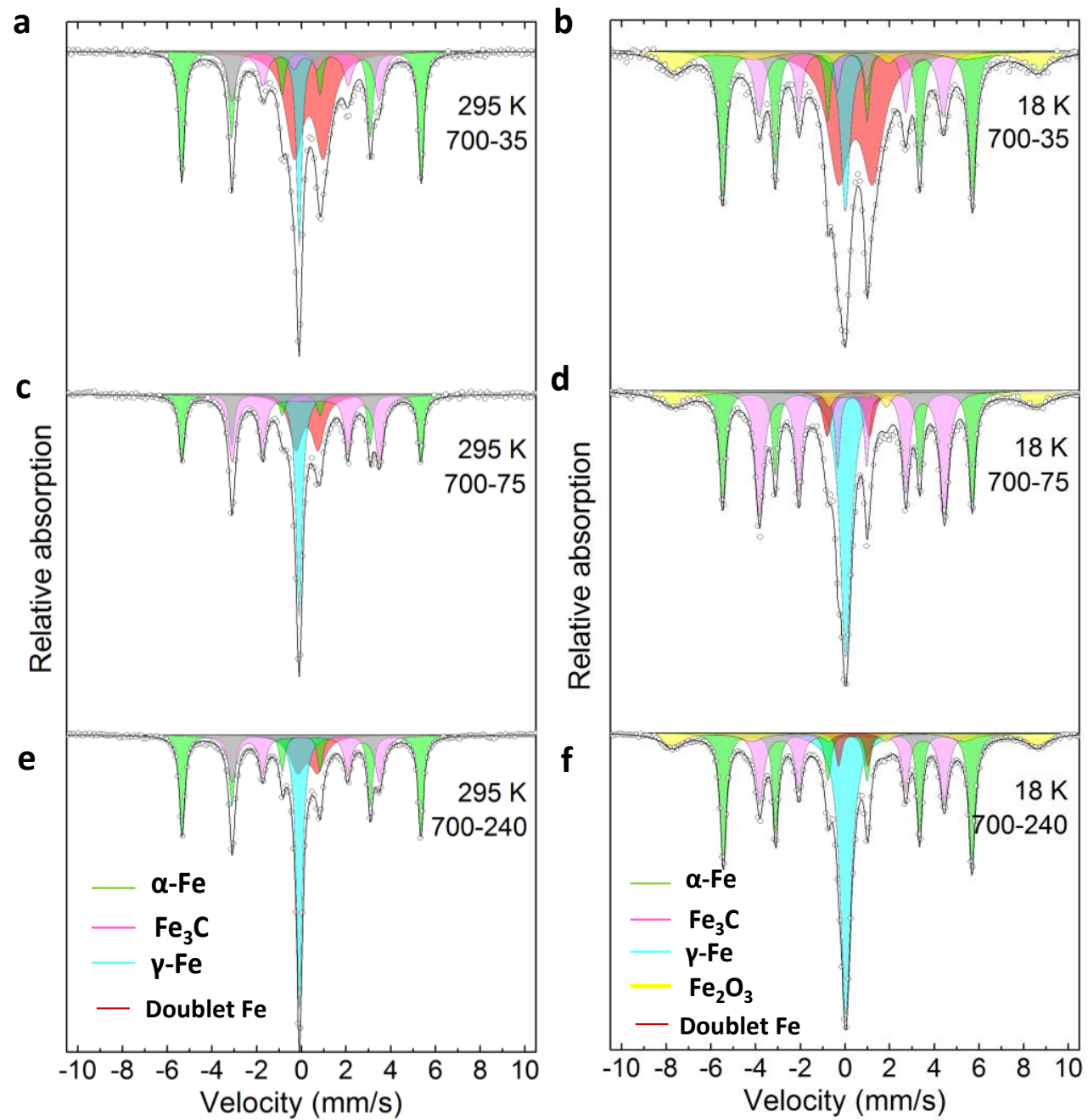

Figure 2. ${ }^{57} \mathrm{Fe}$-Mössbauer spectra obtained at both $298 \mathrm{~K}$ and $18 \mathrm{~K}$ for selected G@ FeNPs samples pyrolyzed at $700^{\circ} \mathrm{C}$ for 30 minutes (a and b), 75 minutes (c and d) and 240 minutes (e and f). 


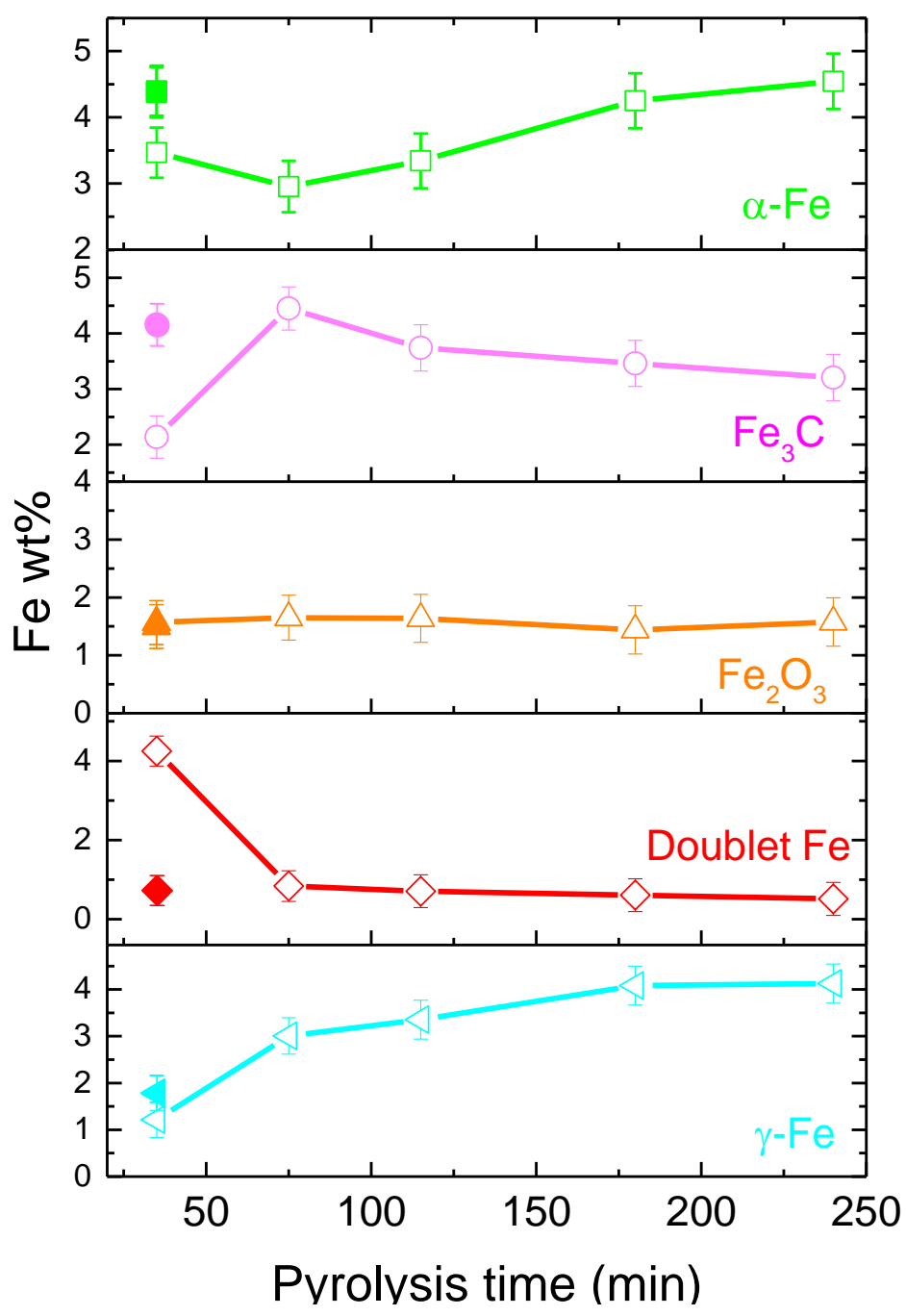

Figure 3. Variation of the content of identified $\mathrm{Fe}$ components $(\% \mathrm{Fe})$ with pyrolysis time at $700{ }^{\circ} \mathrm{C}$ shown in open symbols, while solid symbols were from pyrolysis at $800{ }^{\circ} \mathrm{C}$ for $35 \mathrm{~min}$. The content is based on the total mass of the catalysts as solid powders. The data were obtained from Mössbauer spectra at $18 \mathrm{~K}$. 

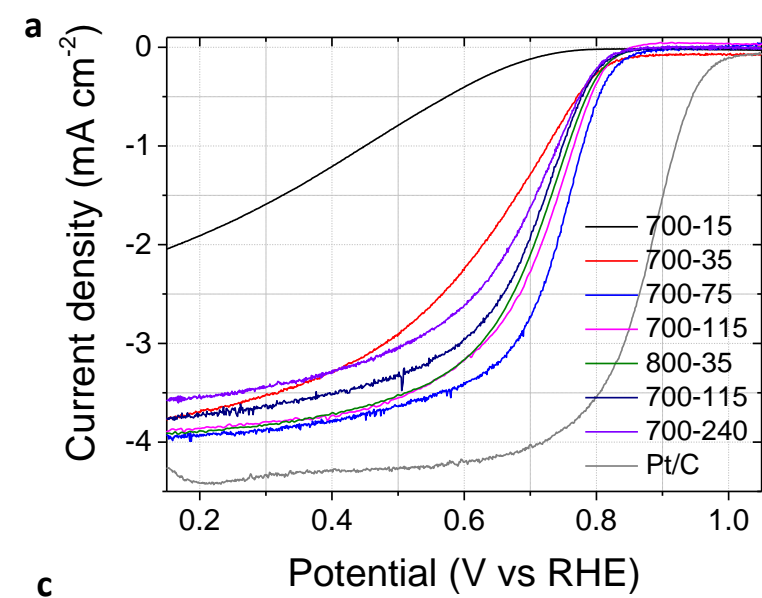

C

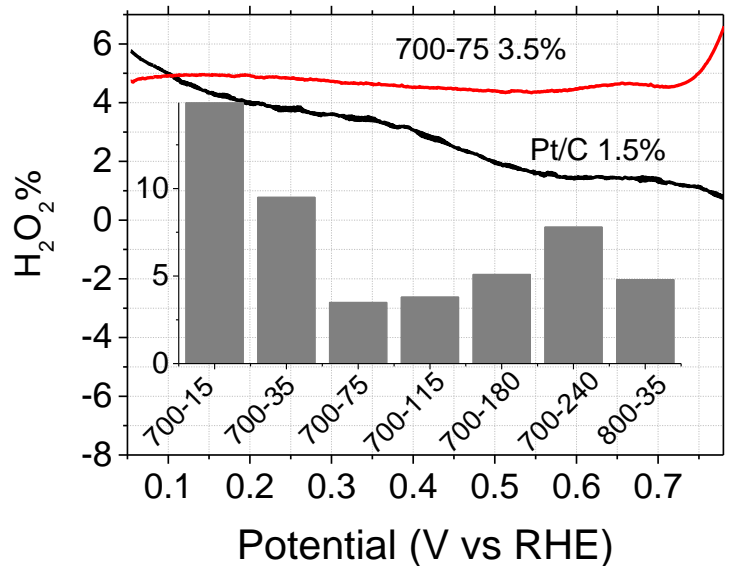

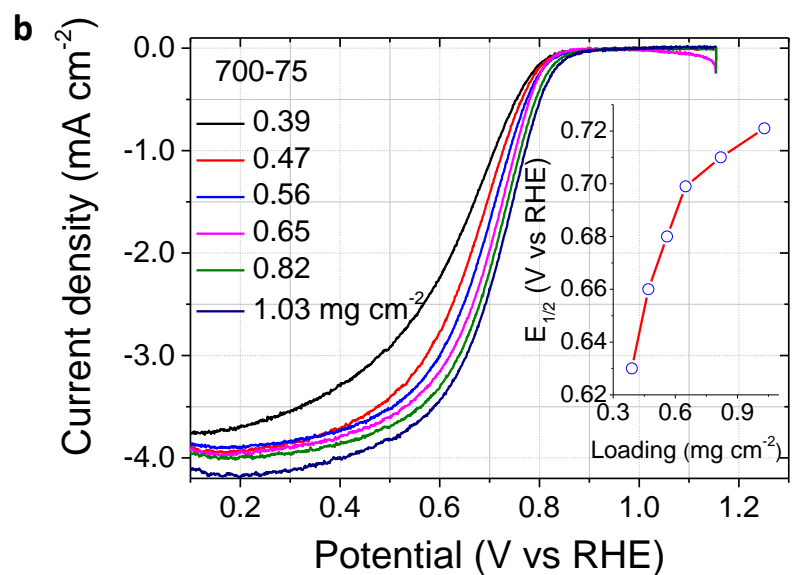

d

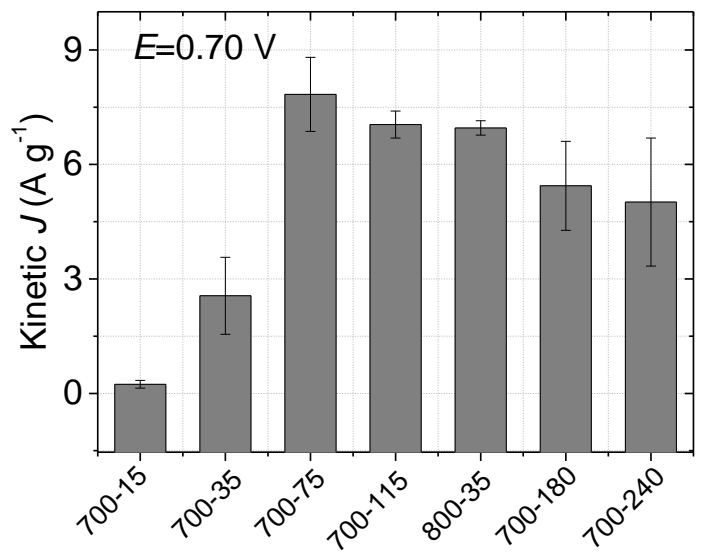

Figure 4. ORR electrochemical activities of G@FeNP catalysts. (a) RDE polarization curves for $\mathrm{G} @ \mathrm{FeNP}$ catalysts in $\mathrm{O}_{2}$-saturated $0.1 \mathrm{M} \mathrm{HClO}_{4}$ solution. The ORR data is replotted from reference 25. The loading of the catalyst was $0.65 \mathrm{mg} \mathrm{cm}^{-2}$ while that of the $20 \% \mathrm{Pt} / \mathrm{C}$ was $0.25 \mathrm{mg} \mathrm{cm}^{-2}$. The rotating speed: $900 \mathrm{rpm}$. (b) RDE polarization curves for catalyst 700-75 at different mass loadings. (c) The $\mathrm{H}_{2} \mathrm{O}_{2}$ yield for 700-75 and $\mathrm{Pt} / \mathrm{C}$ determined from RRDE tests. The insert shows the comparison of the yield for all G@FeNP catalysts at 0.70 V vs. RHE. (d) Comparison of kinetic current density $\left(J_{\mathrm{k}}\right)$ at $0.70 \mathrm{~V}$ vs. RHE for all G@FeNP catalysts. Error bars were obtained from standard deviation of 3-5 independent measurements for each catalyst.

Figure 5a is a plot of the $\mathrm{Fe}_{3} \mathrm{C}$ content and the corresponding mass specific current density $J_{\mathrm{K}}$ for the ORR of the individual catalyst sample. The plot is intended to show the correlation of the carbide content and the ORR activity. It is clearly seen that the two parameters follow the same trends and are peaking for 700-75 in the graph. The $J_{K}$ is further plotted against the $\mathrm{Fe}_{3} \mathrm{C}$ content in Figure 5b. In the whole range of the $\mathrm{Fe}_{3} \mathrm{C}$ content, a strong positive correlation of the electrochemical activity with the $\mathrm{Fe}_{3} \mathrm{C}$ content was observed. 

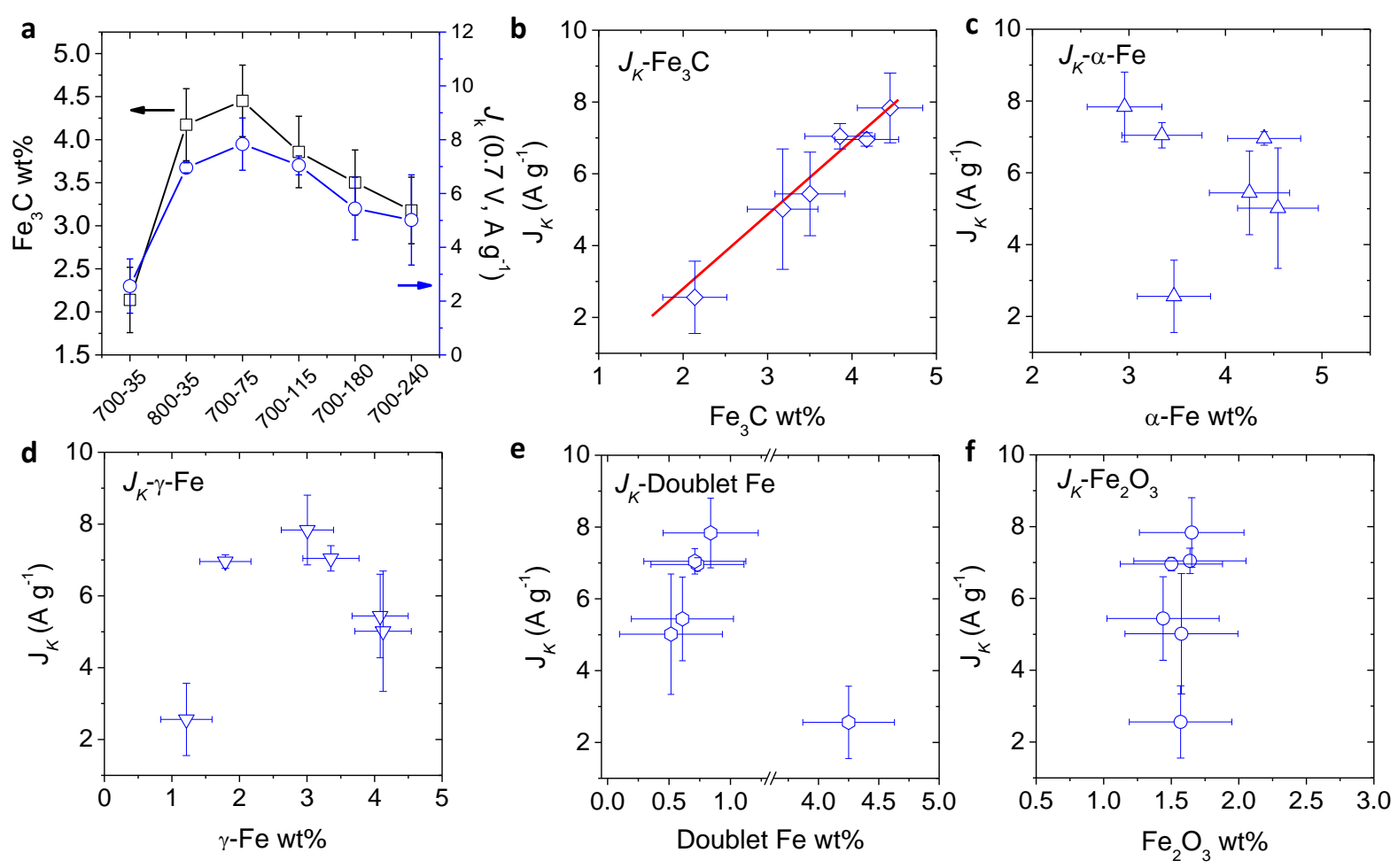

Table 1. Mössbauer parameters at $295 \mathrm{~K}$ and $18 \mathrm{~K}$ for the spectra of samples 700-35, 700-75, 700$115,700-170,700-240$ and 800-35.

\begin{tabular}{|c|c|c|c|c|c|c|c|}
\hline \multicolumn{2}{|c|}{ Component } & $\begin{array}{c}B_{\mathrm{hf}}{ }^{*} \\
\mathrm{~T}\end{array}$ & $\begin{array}{c}\delta^{*} \\
\mathrm{~mm} \mathrm{~s}^{-1}\end{array}$ & $\begin{array}{c}\varepsilon^{*} \\
\mathrm{~mm} \mathrm{~s}^{-1}\end{array}$ & $\begin{array}{c}\Delta^{*} \\
\mathrm{~mm} \mathrm{~s}^{-1}\end{array}$ & $\begin{array}{c}\text { FWHM } \\
\mathrm{mm} \mathrm{s}^{-1}\end{array}$ & Assignment \\
\hline \multirow[t]{2}{*}{ Sextet-1 } & 295 & $33.1-33.2$ & $-0.01-0.00$ & 0.00 & & $0.29-0.32$ & \multirow[t]{2}{*}{$\alpha-\mathrm{Fe}[26,27]$} \\
\hline & 18 & $34.1-34.6$ & $0.11-0.12$ & 0.00 & & $0.32-0.34$ & \\
\hline \multirow[t]{2}{*}{ Sextet-2 } & 295 & $20.4-20.6$ & $0.18-0.19$ & $\begin{array}{l}0.01- \\
0.02\end{array}$ & & $0.45-0.65$ & \multirow[t]{2}{*}{$\mathrm{Fe}_{3} \mathrm{C}[10,26]$} \\
\hline & 18 & $25.2-25.7$ & $0.31-0.32$ & 0.00 & & $0.44-0.47$ & \\
\hline \multirow[t]{2}{*}{ Sextet-3 } & 295 & & - & & & - & \multirow[t]{2}{*}{$\gamma-\mathrm{Fe}_{2} \mathrm{O}_{3}[28,29]$} \\
\hline & 18 & $50.2-50.6$ & $0.43-0.55$ & \begin{tabular}{|l}
$-0.10-$ \\
0.02 \\
\end{tabular} & & $1.10-1.75$ & \\
\hline \multirow[t]{2}{*}{ Doublet } & 295 & & $0.25-0.34$ & & $0.91-1.30$ & $0.57-0.87$ & \multirow{2}{*}{\begin{tabular}{|l}
$\mathrm{Fe}^{3+}(\mathrm{HS})[26,30]$ \\
and/or $\mathrm{Fe}^{2+}(\mathrm{LS})$ \\
{$[10,27,31,32]$}
\end{tabular}} \\
\hline & 18 & & $0.28-0.36$ & & $1.25-1.51$ & $0.18-1.14$ & \\
\hline \multirow[t]{2}{*}{ Singlet } & 295 & & $-0.09--0.10$ & & & $0.31-0.32$ & \multirow[t]{2}{*}{$\gamma-\mathrm{Fe}[26]$} \\
\hline & 18 & & $0.00-0.04$ & & & $0.46-0.58$ & \\
\hline
\end{tabular}

Table 2. Summary of average contents of various Fe components and ORR activities. 


\begin{tabular}{|c|c|c|c|c|c|c|c|c|c|}
\hline \multirow[t]{2}{*}{ Sample } & $\alpha$-Fe & $\mathrm{Fe}_{3} \mathrm{C}$ & $\mathrm{Fe}_{2} \mathrm{O}_{3}$ & Doublet Fe & $\gamma$-Fe & \multirow{2}{*}{$\begin{array}{l}\mathbf{E}_{1 / 2} \\
(\mathrm{~V})\end{array}$} & \multirow{2}{*}{$\begin{array}{c}J_{K}(0.70 \mathrm{~V}) \\
\left(\mathrm{A} \mathrm{g} \mathrm{g}^{-1}\right)\end{array}$} & \multirow{2}{*}{$\begin{array}{c}\mathrm{H}_{2} \mathbf{O}_{2} \\
\%\end{array}$} & \multirow[t]{2}{*}{ ET No. } \\
\hline & \multicolumn{5}{|c|}{ Mass\% (of catalyst) } & & & & \\
\hline $600-35$ & 0 & 0 & 0 & 6.24 & 0.26 & - & - & - & - \\
\hline $700-15$ & 0.27 & 0.55 & 1.18 & 6.83 & 0.18 & $0.232 \pm 0.026$ & $0.24 \pm 0.1$ & 18.0 & 3.64 \\
\hline $700-35$ & 3.47 & 2.14 & 1.57 & 4.25 & 1.21 & $0.635 \pm 0.032$ & $2.56 \pm 1.01$ & 9.5 & 3.81 \\
\hline $700-75$ & 2.95 & 4.45 & 1.65 & 0.84 & 3.01 & $0.720 \pm 0.006$ & $7.84 \pm 0.97$ & 3.5 & 3.93 \\
\hline $700-115$ & 3.34 & 3.74 & 1.64 & 0.71 & 3.35 & $0.713 \pm 0.001$ & $7.05 \pm 0.35$ & 3.8 & 3.92 \\
\hline $700-180$ & 4.25 & 3.46 & 1.44 & 0.61 & 4.08 & $0.697 \pm 0.009$ & $5.44 \pm 1.16$ & 5.1 & 3.90 \\
\hline $700-240$ & 4.54 & 3.18 & 1.58 & 0.52 & 4.12 & $0.679 \pm 0.026$ & $5.01 \pm 1.68$ & 7.8 & 3.84 \\
\hline $800-35$ & 4.40 & 4.17 & 1.50 & 0.73 & 1.79 & $0.712 \pm 0.002$ & $6.96 \pm 0.19$ & 4.8 & 3.91 \\
\hline
\end{tabular}

